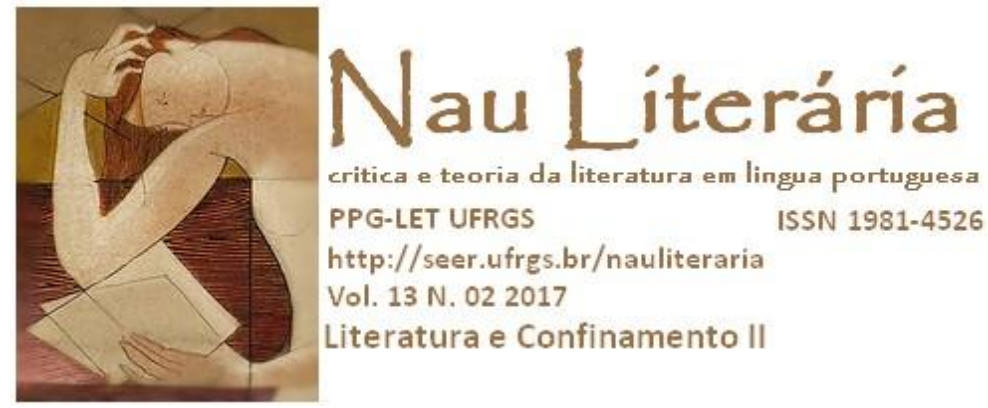

\title{
O confinamento e seus dissabores em Cemitério dos Vivos, Hospício é Deus e Holocausto Brasileiro
}

\author{
Maria Cristina Ferreira dos Santos
}

Resumo: O objetivo deste artigo é analisar como ocorre a representação do hospício e do confinamento nas obras Cemitério dos Vivos, de Lima Barreto, Hospício é Deus, de Maura Lopes Cançado, e Holocausto Brasileiro, de Daniela Arbex. A primeira é uma ficção baseada nas experiências do escritor, a segunda é um relato da estada da autora num sanatório, e a terceira é um romance-reportagem, que denuncia as maldades às quais os pacientes do hospício Colônia, de Barbacena, Minas Gerais, eram submetidos.

Palavras-chave: Hospício; confinamento; representação.

Abstract: The objective of this article is to analyze how the hospice and confinement are represented in the works Cemitério dos Vivos, by Lima Barreto, Hospício é Deus, by Maura Lopes Cançado, and Brazilian Holocaust by Daniela Arbex. The first is a fiction based on the experiences of the writer, the second is an account of the author's stay in a sanatorium, and the third is a novel-report, which denounces the maladies to which the patients of the Cologne hospice, from Barbacena, Minas Gerais, were submitted.

Key words: Hopice; confinement, representation.

\section{Arte e loucura em $O$ cemitério dos vivos}

Na obra $O$ cemitério dos vivos, de Lima Barreto, a personagem-narrador Vicente Mascarenhas é alter-ego do romancista, o qual, através da ficção, relata suas experiências no hospício em que, devido ao alcoolismo, esteve internado três vezes. Através do enredo, questionamentos sobre sua função de escritor e sobre a função da arte na sua vida são levantados, ademais da pertinente descrição desse espaço de privação da liberdade e de sua repercussão na vida dos internados. A obra é dividida em duas partes, a primeira é uma espécie de diário do escritor, a segunda descreve a tragédia doméstica que fora a vida da personagem, com fragmentos alternados entre suas memórias do hospício. 
Logo no início da narrativa, Vicente Mascarenhas descreve a abominação que sentiu ao ser levado ao manicômio pelas mãos da polícia, sendo este ato de submissão às autoridades pior do que o de estar confinado:

Não me incomodo muito com o hospício, mas o que me aborrece é essa intromissão da polícia na minha vida. De mim para mim tenho certeza que não sou louco, mas devido ao álcool, misturado com toda a espécie de apreensões que as dificuldades de minha vida material há seis anos me assoberbam, de quando em quando dou sinais de loucura: deliro. (LIMA BARRETO, 1961, p. 2)

Conforme observado no excerto, a personagem analisa sua própria situação de ser tido como "louco", o que, neste estágio, ele não se considera e, inclusive, encontra justificativas concretas para seus atos desregrados.

Não obstante todas as mazelas que sofre, todos os acanhamentos devido aos seus puderes, sendo um escritor e, antes disso, um grande leitor, Vicente Mascarenhas não esquece de grandes escritores e de grandes personagens, como podemos observar: "Eu me lembrei do banho de vapor de Dostoievski, na Casa dos Mortos. Quando baldeei, chorei, mas lembrei de Cervantes, do próprio Dostoievski, que pior deviam ter sofrido em Argel e na Sibéria" (BARRETO, p. 3). Ele encontra conforto nos literatos e personagens que, na sua concepção, tiveram experiências piores do que as suas, além de sentir certa volúpia do sofrimento, como se fosse algo grandioso sofrer humilhações similares às que grandes nomes da Literatura Mundial estiveram submetidos. Esse raciocínio se complementa quando o narrador de $O$ cemitério dos vivos declara: "Ah! A Literatura ou me mata ou me dá o que eu peço dela" (LIMA BARRETO, p. 3). É como se seu relato fosse um grande questionamento do que ele esperava da arte e do que esta lhe ofereceu. Torna-se, destarte, uma obra metalinguística, na medida em que põe em xeque a função da literatura. E obviamente demonstra o rancor sempre latente do escritor Lima Barreto de não ter sido reconhecido como esperava. É pertinente frisar o caráter de pharmakon que a citação acima demonstra, aquele já preconizado por Platão, a saber, o de que a arte pode ser tanto veneno como remédio. No caso da personagem de Lima Barreto, pode tanto salvá-lo como matá-lo.

Além disso, há constantes críticas aos intelectuais, ou àqueles que se dizem eruditos: "Decididamente, a mocidade acadêmica, de que fiz parte, cada vez fica mais presunçosa e oca” (LIMA BARRETO, p. 3). A personagem, desiludida devido a sua situação, não raras vezes, declara, ao analisar algum companheiro de internamento, que a presunção à intelectualidade torna a pessoa esnobe e repugnante. 
Quanto ao ambiente, a personagem o descreve como pobre e degradante, apesar de haver cuidados higiênicos, como na seção Pinel. Um dos fatores que chama a atenção do leitor é como Lima Barreto relata com ternura a profissão dos enfermeiros e ajudantes do hospício, como se todos fossem de uma docilidade quase surreal. Dispende páginas e páginas, ao longo do enredo, para discorrer sobre a paciência e a dedicação dos funcionários e ao quanto lamenta por eles dedicaram sua existência a tão degradante função, pois a mesma exige abdicação a diversos encantos da vida: "[...] tudo isto e o que se pode facilmente adivinhar, transforma a vida desses guardas, enfermeiros, num verdadeiro sacerdócio" (LIMA BARRETO, p. 5).

No entanto, chega a ser duvidosa a afirmação do narrador de $O$ cemitério dos vivos de que os funcionários do hospício eram atenciosos e pacientes com os internos, pois, em outros relatos, fictícios ou autobiográficos, acerca de casas de internação para dementes, os médicos, os enfermeiros e demais funcionários são, a grande parte, descritos como tendo conduta extremamente brutal. Exemplos são o longa-metragem Nise, o coração da loucura, e a narrativa de Maura Lopes Cançado, Hospício é Deus (2015), em que a escritora relata diversos casos de abuso e brutalidades de enfermeiros e médicos, inclusive o fato de eletrochoques serem usados como punição ou vingança, e não como tratamento.

No capítulo III da primeira parte de $O$ cemitério dos vivos, a personagem faz uma análise dos motivos que a levaram a sucumbir ao alcoolismo, e a conclusão pode ser considerada como paranoia, pois afirma que não foram os problemas reais que o influenciaram, mas a angústia de um porvenir decadente, de uma catástrofe doméstica e de miséria extrema. No início, para fugir destas possíveis mazelas, começou com cerveja e depois viu a decadência, entregando-se ao consumo da cachaça pura, estando, muitas vezes, bêbado já as nove horas da noite. Sobre a época em que chegou ao ápice do vício, declara: "Não me preocupava com o meu corpo. Deixava crescer o cabelo, a barba, não me banhava a miúdo. Todo o dinheiro que apanhava bebia. Delirava de desespero e desesperança; eu não obteria nada" (LIMA BARRETO, p. 9).

Logo, questiona-se e tenta analisar o que define a loucura e quem a pode diagnosticar e curar, e chega à conclusão de que não há uma definição, tampouco cura para um estado de alucinação. E pertinentes são suas indagações acerca de outros estados compulsivos que não são tidos pela ciência como loucuras, como o amor obsessivo, a busca da riqueza e da notoriedade. Ademais, declara que "O nosso sistema de tratamento da loucura ainda é o da 
Idade Média: o sequestro" (LIMA BARRETO, p. 20). Ou seja, não existe definição científica da loucura tampouco tratamento eficaz. Nesse entrementes, aproveita para relatar que há doentes que têm regalias no hospício pelo fato de terem alguma influência política.

A escolha do título da obra não é fortuita, pois literalmente Lima Barreto dá indícios em seu enredo de que o confinamento em um sanatório degrada o ser humano a tal ponto que esta vivência é pior do que a morte, como podemos observar nesta análise dos pacientes que convivem com a personagem de $O$ cemitério dos vivos: "Todos eles estão na mão de um poder que é mais forte do que a Morte. A esta, dizem, vence o amor, a Loucura, porém, nem ele" (LIMA BARRETO, p. 21).

E, tratando de decadência e destino mais draconiano do que a morte, a personagem Vicente Mascarenhas deseja sair do manicômio e, ao mesmo tempo, repele este acontecimento, pois define sua casa como uma sala mortuária, uma vez que seu filho tem retardo mental, sua esposa faleceu sem ser amada por ele e sua sogra é insana.

Ao findar a primeira parte do livro, descreve seu amor à biblioteca do hospício, descreve algumas obras que leu, e faz, além disso, algumas descrições aleatórias do ambiente, dos colegas e das conversas que tivera com companheiros de internamento.

A segunda parte do livro é dedicada, especialmente, à descrição das peripécias domésticas da parte de sua vida anterior ao vício e aos internamentos por insanidade. Relata suas experiências de jovem tímido que nunca teve ganas de romance e que acabou casando sem amor e sem entusiasmo com a rapariga que, contrariando os costumes da época, propusera-lhe casamento. A narrativa, dessa forma, torna-se catártica, na medida em que declara seus arrependimentos de não ter amado sua esposa, nem seu filho, nem ninguém, e de não ter sido feliz profissionalmente.

A partir desta etapa da narrativa, a personagem começa a ver beleza na decadência, sem nunca deixar de comparar-se com grandes literatos:

[...] pareceu-me que ver a vida assim era vê-la bela, pois acreditei que só a tristeza, só o sofrimento, só a dor faziam com que nós nos comunicássemos com o Logos, com a Origem das Coisas e de lá trouxéssemos alguma coisa transcendente e divina. (LIMA BARRETO, p. 59)

Francisco de Assis Barbosa escreveu A vida de Lima Barreto (1964), obra em que esmiúça os livros do autor carioca, relacionando-os com sua vivência decadente de mulato 
que sofrera preconceitos e que se entregara ao alcoolismo, vício este que o privou, em alguns casos, da notoriedade literária que tanto almejara, como descreve no excerto a seguir:

\begin{abstract}
O boêmio se despedia da vida, abolindo todas as conveniências. Monteiro Lobato, que viera ao Rio, especialmente para conhecê-lo, um ano depois do lançamento do Vida e Morte de M.J. Gonzaga de Sá, localizara Lima Barreto numa das tascas do centro da cidade, mas em tal estado que não tivera ânimo para se apresentar àquele que considerava o maior de todos os nossos romancistas. (BARBOSA, 1964, p. 290)
\end{abstract}

Assis Barbosa divide sua análise em partes, conforme as fases da vida de Lima Barreto, e o capítulo dedicado ao $O$ cemitério dos vivos é sugestivamente chamado de Declínio.

O desfecho metafórico de $O$ cemitério dos vivos: "Fiquei eu só no vão da janela" (LIMA BARRETO, p. 91) resume a vida não só da personagem, mas também a do escritor, pois ambos personificaram a decadência através de ações autodestrutivas e acabaram enredados pela pior de suas paranoias, a saber, a de estar sozinho e inglório.

\title{
2 Hospício é Deus
}

Maura Lopes Cançado, de acordo com sua narrativa de cunho intimista Hospício é Deus, é oriunda de uma grande e abastada família do interior de Minas Gerais, fora uma criança bela e mimada, com forte relação afetiva com o pai, relacionamento que trará consequências por toda a vida, inclusive durante os períodos de tratamento em que esteve internada em diferentes hospícios. Ao descrever seu pai, o trata com grande carinho, porém, enaltece o fato de ter sido um homem forte e histérico, entrementes aos excessos de afetividade para com a sua filha predileta, Maura. A narradora o descreve com sensibilidade:

Aquele homem, vivendo à margem da civilização, aquele homem temido e forte, possuía uma dimensão desconhecida a si mesmo. Podia ter sido um Wagner, um Nietzsche ou um Napoleão. Não fora a limitação do seu meio, seria o maior homem do mundo. Mas dentro do seu mundo, foi o maior personagem que conheci. (CANÇADO, 2016, p. 10)

Logo, admite que tinha uma convivência difícil com suas irmãs, especialmente as mais novas, e declara que sempre fora protegida: "Sim, costumava mostrar-me demais manhosa, ninguém ousava contrariar-me, o que seria contrariar papai. Algumas das minhas irmãs maiores tomavam a defesa de Selva, em nossas brigas” (CANÇADO, 2016, p. 13).

Surpreendente é que Maura Lopes Cançado analisa a si mesma como sendo, desde idade pueril uma "[...] candidata aos hospícios onde vim parar. O medo foi uma constante em minha vida" (CANÇADO, 2016, p. 13). Sua análise esmiúça os motivos de ter sido uma 
criança desequilibrada e dá indícios de que, muito cedo reconhecendo o ato sexual ao observar animais, ficara curiosa e fora admoestada de ser este um ato sujo e feio. Mais contundente é a relação que estabeleceu, a partir da descoberta do sexo, com Deus, como um ser que, segundo o que lhe diziam, era tenaz, vingativo e onipresente: "Minhas relações com Deus foram as piores possíveis - eu não me confessava odiá-lo por medo da sua cólera. Mas a verdade é que fugia-lhe como julgava possível - e jamais o amei. Deus foi o demônio da minha infância" (CANÇADO, 2016, p. 17).

Relata, mais adiante, cenas de estupro por empregados da fazenda de seu pai e as primeiras vezes em que teve ataque epiléptico e gostou de ser o centro das atenções. Aliás, discorre também sobre sua necessidade constante de afirmação e sobre o fato de que estudou em diversos colégios, nunca se adaptou em nenhum, e que, apesar de nunca se dedicar, sempre fora uma aluna acima da média.

Seguindo com seus atos de menina mimada, casou-se, aos 14 anos, com um piloto que conhecera em suas aulas de aviação, simplesmente, como ela mesmo admite, por capricho, sem amor e sem comprometimento: "Casada, pensei logo em me descasar, tão imediata foi a decepção. Talvez oito dias depois" (CANÇADO, 2016, p. 21). O casamento, do qual concebeu um filho, durou apenas um ano, e o divórcio, somado à morte de seu pai e ao fato de ser, numa sociedade conservadora, uma mulher divorciada aos 15 anos de idade, marcaram negativamente sua visão de mundo. Começou a ler filósofos niilistas, tendo, dessa forma, visão completamente negativa do mundo, não se sentia adaptada a nenhum ambiente, julgava sua família inferior a ela intelectualmente e a sociedade a repugnava por já ter sido casada:

Desde então tudo tomou caráter mais grave e penoso, passei a sofrer com brutalidade os reflexos do condicionamento imposto a uma adolescente numa sociedade burguesa, principalmente mineira - e principalmente quando esta adolescente julga perceber além das verdades que lhe impõem, e tem, ela mesma, sua verdade própria. (CANÇADO, 2016, p. 24)

Junto às suas reminiscências de infância e adolescência, Maura Lopes Cançado descreve o ambiente hostil do sanatório em que se encontra quando redigiu as páginas de seu diário que depois se tornariam a obra Hospício é Deus.

Numa das primeiras menções que faz ao hospício, conclui que poucos são os loucos que estão internados, a maioria são pessoas que buscam a cura para uma doença que não possuem e o fazem por ser o único objetivo que têm na vida. A concepção da autora sobre a morte muda ao longo dos anos e ao longo do enredo, se o tomarmos cronologicamente, pois, quando criança, era atormentada pela ideia de morte, tinha horror em pensar que seria 
enterrada, ou que, conforme a crença que tentaram lhe incutir, iria para o inferno. Porém, já adulta e internada, pensa na morte como a completude do Ser, visão análoga a do filósofo Martin Heidegger (2002), para quem o ser só se completa com a morte. Nas palavras de Maura Lopes Cançado: "Também se luta contra a morte, quando morrer talvez seja realizarse" (CANÇADO, 2016, p. 25).

Ao descrever o hospício, declara:

Há tempos escrevi um conto, no qual dizia ser aqui "uma cidade triste de uniformes azuis e jalecos brancos" Esta cidade se compõe de seis edifícios, abrigando, normalmente, creio, dois mil e quinhentos habitantes (não estou bem certa do número). Doentes mentais ou como tais considerados. Além do hospital onde me encontro existem: IP (Instituto de Psiquiatria), onde se fazem internações (estive lá dois meses. É caótico), Bloco Medico-cirúrgico, Isolamento (Hospital Braule Pinto - doenças contagiosas, tuberculose principalmente), Hospital Pedro II e Instituto de Neuropsiquiatria Infantil. O Isolamento fica aqui perto. Á noite, se não consigo dormir, ouço gritos dos doentes de lá. Não compreendo um hospital abrigando tuberculosos no Engenho de Dentro, onde o clima é o mais quente do Rio. (CANÇADO, 2016, p. 30)

O ambiente é tão precário que, para escrever, ela empresta um toco de lápis de outra interna. Faz muito frio e suas vestes são escassas, usa apenas uma bata de tecido ralo, sem peças íntimas. Crê que, ao relatar suas experiências poderia “[...] mandar aos que não sabem uma mensagem do nosso mundo sombrio" (CANÇADO. 2016, p. 31).

Os dias custam a passar e a rotina é insuportável. As funcionárias do hospício são denominadas pela narradora de guardas e, segunda ela, são brutais, parecem se divertir ao maltratar as pacientes, falam-lhe palavrões e as agridem constantemente. A comida é insossa, e, pior do que isso, é o ambiente do refeitório, em que dementes malcheirosas se amontoam e brigam, gritam, jogam comida e utensílios umas nas outras.

Sua relação com o médico, a quem nomenclatura de Dr. A., é contraditória e, muitas vezes, não profissional, na medida em que a escritora se declara diversas vezes a ele, tentando seduzi-lo. Ele é negro, belo e, segundo a narradora, menos inteligente do que ela. Maura Lopes Cançado considera chistosas as análises de psicoterapia do Dr. A., pois, para ele, assim como para outros psiquiatras, tudo no discurso do paciente é simbólico e remete ao estado de demência.

$\mathrm{O}$ ato de escrever é constantemente descrito, analisado e visto como fuga da realidade iníqua em que se encontra, diversas vezes remete ao fato de estar escrevendo o conto $O$ sofredor do ver, o qual the dera muito trabalho. 
Muitas vezes não consegue organizar suas ideias e declara: "Não possuo nenhum equilíbrio emocional. Passo de grande exaltação para profunda depressão" (CANÇADO, 2016, p. 37).

Múltiplas vezes a escritora de Hospício é Deus adverte o leitor sobre os médicos do sanatório, declarando-os tão loucos quanto os internos. E, assim como Lima Barreto em $O$ cemitério dos vivos, questiona-se sobre o diagnóstico da loucura e suas distintas manifestações, pois quem a pode diagnosticar? Como é estabelecido um padrão? Ademais, no hospício em que está internada, os médicos não respeitam as idiossincrasias de cada paciente, submetendo todos, muitas vezes, ao mesmo tratamento, a saber, eletrochoque, como ocorreu com a narradora. Num diálogo com o médico que estivera tratando-a, Maura afirma:

Possuo dois eletroencefalogramas anormais, fui vítima de crises convulsivas até os quinze anos. Um dos eletros está dentro de minha papeleta, ou ficha. Como meu médico, o senhor devia ter-se inteirado antes, e o respeitado. Fez o eletrochoque por vingança e para castigar-me. Este método é muito usado pelos psiquiatras, sei. Eletrochoque devia ser tratamento, e não instrumento de vingança em mãos de irresponsáveis. Mas, aqui, até as guardas ameaçam doentes com eletrochoques, trazendo-as em constante estado de tensão nervosa. (CANÇADO, 2016, p. 43)

Para ela, a escrita tem uma função específica, a de relatar os horrores de um hospício, alertar a sociedade acerca do que os ditos doentes mentais sofrem na clausura: "Se me tornar escritora, até mesmo jornalista, contarei honestamente o que é um hospital de alienados. Propalam uma série de mentiras sobre estes hospitais: que o tratamento é bom, tudo se tem feito para minorar o sofrimento dos doentes. E eu digo: É MENTIRA (CANÇADO, 2016, p. 49).

Ao seguir seu fluxo de consciência, Maura Lopes Cançado analisa a determinação do meio em que vivemos na formação de nosso caráter. Segundo a escritora, somos condicionados por isso:

Mas verdadeiramente somos filhos da terra em que nascemos, é ela que determina nosso
comportamento, ainda nossos pensamentos, na medida em que nos influencia. Em Belo
Horizonte, cercados por montanhas, somos fundidos a ferro e fogo. Montanha, ferro, pedras,
minério - transforma-nos em seres rijos, pensantes e mais cruéis. Ainda o amor é transformado
pela paisagem em algo cerebral, uma ávida cerebralização de ternura que não afasta a solidão:
antes, exacerba-a mais ainda. Eu não seria hoje o que sou se não fosse mineira. A Minas devo o
meu caráter introspectivo, minha busca constante do absoluto e a disciplina que consigo me
impor quando o desejo, essencial ao estudo e à criação. E conservo mesmo certo desprezo
pelos filhos de outras paisagens amenas, porém lassas. (CANÇADO, 2016, p. 67)

A narradora demonstra caráter onipresente, onisciente e de olhar cinematográfico, pois, ao ler o enredo, temos a impressão que descreve cenas de um filme, chegando a afirmar 
que muitas descrições que tenta fazer só seriam perfeitamente captadas por câmeras. Onipresente porque tem visão acurada de todos os setores do sanatório, onisciente porque parece conhecer os problemas de cada um e os narra com precisão. Ao mesmo tempo que observa, é também perseguida pela sensação de estar sempre sendo analisada: "Em cada canto, olhos cor-de-rosa e frios espiam sem piscar. Os dias neutros. As tardes opacas, vazias, quando um ruído assusta, como vida, surgida, rápida, logo apagada - extinta" (CANÇADO, 2016, p. 75).

A parecença com o enredo de Lima Barreto, O cemitério dos vivos, mais uma vez fica latente quando faz esta descrição: "Os dormitórios vazios e impessoais são cemitérios, onde se guardam passado e futuro de tantas vidas. Cemitérios sem flor e sem piedade: cada leito mudo é um túmulo, e eu existo entre o céu e esta dormência calada" (CANÇADO, 2016, p. 75).

Ao escrever seu diário, que depois seria publicado, Maura Lopes Cançado conseguiu se desviar da anulação de identidade a que os internos de um hospício estão submetidos. Dessa forma, salvou-se do esquecimento que poderia advir se apenas morresse no hospício sem ter redigido suas rememorações, e foi capaz de mostrar aos leitores suas idiossincrasias.

\section{Holocausto Brasileiro: genocídio no maior hospício do Brasil}

Daniela Arbex é uma respeitável jornalista que, diferente dos outros dois escritores supramencionados, não esteve internada em um hospício, porém se dedicou a pesquisar e escancarar para a sociedade as maldades a que os pacientes do Colônia - manicômio da cidade de Barbacena, Minas Gerais - eram submetidos. Tendo como meta não deixar que este horrendo fragmento da história do Brasil fosse acobertado ou esquecido, pois sessenta mil pessoas foram mortas por eletrochoque, inanição, frio, maus tratos, entre outros.

O pior aspecto narrado por Daniela é que a grande maioria dos pacientes não tinham sequer um diagnóstico de loucura digno de uma internação, mas eram moças que perderam a virgindade antes de casar, mulheres cujos maridos queriam viver com suas amantes, meninas que estavam grávidas por terem sido estupradas por seus patrões, alcoolistas, homossexuais, rebeldes, tímidos, usuários de maconha, pessoas que não tinham documento de identificação, entre outros. Isso demonstra que o maior e mais repugnante hospício do Brasil serviu como depósito de pessoas que eram, de alguma maneira, rejeitadas pela família ou pela sociedade. 
Pior do que a falta de diagnósticos e, também de médicos psiquiatras, eram as condições a que os pacientes eram submetidos, a saber, andavam nus, mesmo com a temperatura baixa da Serra da Mantiqueira, bebiam água do esgoto e, muitas vezes, pela escassez de comida, alimentavam-se de ratos e até de fezes, e um dos castigos para os mais "rebeldes" era mergulhá-los em uma banheira de excrementos. Outro fato espantoso descrito pela jornalista é que:

Ao morrer, davam lucro. Entre 1969 e 1980, 1853 corpos de pacientes do manicômio foram vendidos para dezessete faculdades de medicina do país, sem que ninguém questionasse. Quando houve excesso de cadáveres e o mercado encolheu, os corpos foram decompostos em ácido, no pátio do Colônia, na frente dos pacientes, para que as ossadas pudessem ser comercializadas. Nada se perdia, exceto a vida. (ARBEX, 2013, p. 14)

Por isso, ela intitula seu livro de Holocausto Brasileiro, na medida em que um paciente enviado para o Colônia dificilmente sobreviveria por muito tempo, era muito semelhante a ser enviado a um campo de concentração nazista, pois não eram tratados como se esperava, mas maltratados e deixados para morrer da forma mais desumana.

A autora entrevistou ex-funcionários, os quais têm impressão semelhante a dela quanto à precariedade da instituição. Um exemplo é Marlene Laureano, que havia passado em um concurso do estado, sem saber que sua vaga seria destinada à Casa de Loucos, como também era conhecido o hospício. Em suas palavras, confirma-se o supramencionado: "Começara a trabalhar num campo de concentração travestido de hospital. Apesar de estar tomada pela indignação, sentiu-se impotente diante da instituição tradicional que mantinha, com o apoio da Igreja Católica, as portas abertas desde 1903" (ARBEX, 2013, p. 25).

Outro fato lembrado por uma ex-funcionária é do "trem de doido", no qual chegavam os novos pacientes:

A parada na estação Bias Fortes era a última da longa viagem de trem que cortava o interior do
país. Quando a locomotiva desacelerava, já nos fundos do Hospital Colônia, os passageiros se
agitavam. Acuados e famintos, esperavam a ordem dos guardas para descer, seguindo em fila
indiana na direção do desconhecido. Muitos nem sequer sabiam em que cidade tinham
desembarcado ou mesmo o motivo pelo qual despachados para aquele lugar. Os deserdados
sociais chegavam a Barbacena de vários cantos do Brasil. Eles abarrotavam os vagões de carga
de maneira idêntica aos judeus levados, durante a Segunda Guerra Mundial, para os campos de
concentração nazista de Auschwits. (ARBEX, 2013, p. 27)

A propósito, a expressão "trem de doido" foi criada pelo escritor João Guimarães Rosa no conto Sorôco, sua mãe, sua filha, do livro Primeiras estórias, lançado em 1962. Nele, o autor resgata a trajetória de pessoas enviadas de trem ao maior hospício do Brasil através da 
personagem principal, que é um homem que se despede dos únicos parentes que tinha, e os quais nunca mais tornaria a ver, pois têm como destino Barbacena em busca de tratamento psiquiátrico. Como podemos ver na descrição do autor:

Não era um vagão comum de passageiros, de primeira, só que mais vistoso, todo novo. A gente reparando, notava as diferenças. Assim repartido em dois, num dos cômodos as janelas sendo de grades, feito as de cadeia, para os presos. A gente sabia que, com pouco, ele ia rodar de volta, atrelado ao expresso daí de baixo, fazendo parte da composição. Ia servir para levar duas mulheres, para longe, para sempre. $\mathrm{O}$ trem do sertão passava às $12 \mathrm{~h} 45 \mathrm{~m}$. (ROSA, 2008, p. 62)

Mais adiante, podemos perceber como o escritor retrata a maneira que os "loucos" eram tratados pela sociedade, pois vendo o sofrimento de Sorôco ao despachar sua mãe e sua filha para um lugar de onde jamais retornariam, pessoas tentam conformá-lo, classificando-as como incômodos, dos quais ele deve se livrar:

O que os outros se diziam: que Sorôco tinha tido muita paciência. Sendo que não ia sentir falta dessas transtornadas pobrezinhas, era até um alívio. Isso não tinha cura, elas não iam voltar, nunca mais. De antes, Sorôco aguentara de repassar tantas desgraças, de morar com as duas, pelejava. Daí, com os anos, elas pioraram, ele não dava mais conta, teve de chamar ajuda, que foi preciso. Tiveram que olhar em socorro dele, determinar de dar as providências, de mercê. Quem pagava tudo era o governo, que tinha mandado o carro. Por forma que, por força disso, agora iam com as duas, em hospícios. O se seguir. (ROSA, 2008, p. 64)

Além de mencionar o "trem de doidos" que levava os pacientes, e mostrar outras mazelas do hospício, Daniela Arbex também entrevistou alguns dos poucos que sobreviveram a este holocausto e que puderam de lá sair. Porém, tão triste quanto pensar em sua estada no Colônia, é refletir sobre o que este tempo lhes roubou de convívio social e de momentos "normais". Um exemplo é Antônio Gomes da Silva, que ficou trinta e quatro anos no hospício, e até hoje não sabe o motivo de sua internação. Dentro da unidade, manteve-se calado por quase vinte e um anos, pois ninguém nunca lhe perguntou nada. Hoje, mora numa residência terapêutica de Barbacena, e seu depoimento é comovente:

Retirado do convívio social por quase maio século, ele jamais poderia imaginar que agora era dono do seu tempo e que tinha ele mesmo o poder de clarear ou escurecer o ambiente com um simples toque no interruptor. Além de nunca ter visto um apagador de luz, ser dono de si era uma novidade para quem viveu décadas de institucionalização. Para Antônio, no entanto, se desvencilhar do Colônia foi tão difícil quanto mudar de endereço. O hospital estava ali, marcado não só em seu corpo, mas também impregnado em sua alma. Por isso, os pesadelos tornavam seu sono sobressaltado e se repetiam noite após noite. Acordava com o suor umedecendo o pijama e sempre com a mesma sensação de terror. Olhava ao redor para ver onde estava e descobria que os eletrochoques com os quais sonhava ainda o mantinham prisioneiro do Colônia. (ARBEX, 2013, p. 33) 
Outro aspecto do Colônia descrito pela jornalista é que muitas pacientes engravidavam por manterem relações com outros internos e, muitas vezes, por serem estupradas por funcionários. Porém, seus filhos eram arrancados de seus braços tão logo nasciam, o que ajudava a agravar o quadro de degradação dos direitos.

Daniela Arbex sente-se gratificada pela pesquisa e publicação de Holocausto Brasileiro, pois:

O fato é que a história do Colônia é a nossa história. Ela representa a vergonha da omissão coletiva que faz mais vítimas no Brasil. Os campos de concentração vão além de Barbacena. Estão de volta nos hospitais públicos lotados que continuam a funcionar precariamente em muitas outras cidades brasileiras. Multiplicam-se nas prisões, nos centros de socioeducação para adolescentes em conflito com a lei, nas comunidades à mercê do tráfico. O descaso diante da realidade nos transforma em prisioneiros dela. Ao ignorá-la, nos tornamos cúmplices dos crimes que se repetem diariamente diante de nossos olhos. Enquanto o silêncio acobertar a indiferença, a sociedade continuará avançando em direção ao passado de barbárie. É tempo de escrever uma nova história e de mudar o final. (ARBEX, 2013, p. 255)

Como sabiamente declarou a jornalista, impedir a cultura do silêncio em relação a histórias de barbárie como a do hospício Colônia é obrigação de intelectuais, é tempo de pesquisar, discutir e mostrar ao mundo o que aconteceu, e ainda ocorre, nas prisões disfarçadas de hospitais para dementes.

\section{À guisa de conclusões}

Sempre que trato de literatura, principalmente de obras que abordam temas fortes como guerras, Nazismo, trauma, extermínio, loucura, e penso no impacto que elas têm em minha atuação como leitora e analista, lembro-me de uma declaração de Erico Verissimo, em seu livro de memórias, na qual alerta:

Desde que, adulto, comecei a escrever romances, tem-me animado até hoje a ideia de que o menos que um escritor pode fazer, numa época de atrocidades e injustiças como a nossa, é acender a sua lâmpada, fazer luz sobre a realidade de seu mundo, evitando que sobre ele caia a escuridão, propícia aos ladrões, aos assassinos e aos tiranos. Sim, segurar a lâmpada, a despeito da náusea e do horror. Se não tivermos uma lâmpada elétrica, acendamos o nosso toco de vela ou, em último caso, risquemos fósforos repetidamente, como um sinal de que não desertamos nosso posto. (VERISSIMO, 1974, p. 45)

Não só os escritores, mas os estudiosos de literatura também devem segurar a lâmpada, ou riscar o fósforo. E foi isso que procurei fazer neste artigo, ou seja, trazer à luz a realidade do enclausuramento para que, de alguma forma, as vozes dos escritores como Lima Barreto e Maura Lopes Cançado que, a despeito de inóspitas situações, nos deixaram o legado 
de suas experiências, ou, ainda, da jornalista Daniela Arbex, que se dedicou à pesquisa do horrendo hospício Colônia, não fossem sufocadas ou esquecidas.

\section{Referências}

ARBOX, Daniela. Holocausto Brasileiro. 3 ed. São Paulo: Geração Editorial, 2013.

BARBOSA, Francisco de Assis. A vida de Lima Barreto. 3 ed. Rio de Janeiro: Civilização Brasileira, 1964.

BARRETO, Lima. O cemitério dos vivos. Domínio público. Acesso em 20/08/2016.

CANÇADO, Maura Lopes. Hospício é Deus. Belo Horizonte: Autêntica, 2015.

HEIDEGGER, Martin. Ser e tempo. Trad. de Márcia Sá Cavalcante. 9. ed.. Petrópolis: Vozes, 2002. Parte II.

ROSA, João Guimarães. Primeiras estórias. Rio de Janeiro: Lacerda Editores Ltda, 2008.

VERISSIMO, Erico. Solo de Clarineta. Vol I. 4 ed. Porto Alegre: Globo, 1974. 